\title{
COMMINUTED FRACTURES OF DISTAL FEMUR- A STUDY ON LIMITED DISSECTION FOR INTERNAL FIXATION
}

\author{
P. Anil Babu' ${ }^{1}$ M. Prasanth ${ }^{2}$
}

${ }_{1}^{1}$ Assistant Professor, Department of Orthopaedics, Guntur Medical College, Guntur, Andhra Pradesh. ${ }^{2}$ Former Professor and HOD, Department of Orthopaedics, Guntur Medical College, Guntur, Andhra Pradesh. ABSTRACT

\section{BACKGROUND}

Supracondylar fracture of femur occurs in a variety of situations. In high velocity trauma, the impact is so high that these fractures occur with comminution and compromised soft tissue cover.

\section{MATERIALS AND METHODS}

Our study consists of 29 cases of supracondylar fractures of femur with intercondylar extension, wherein fracture reduction is required in all planes. We have performed these surgeries with one approach and manoeuvring the multiple fragments for alignment by limiting the dissection, for distal femoral plate, for this study.

\section{RESULTS}

We could reduce the fragments with near anatomical congruity at the distal femur with single approach.

\section{CONCLUSION}

High impact supracondylar fractures can be reduced with anterolateral approach and manoeuvring the fragments on medial condyle with limited dissection, by keeping the Gastrocnemius in relaxed position. It saves another incision and soft tissue cover on the medial side and the skin which has already suffered from the impact of the trauma.

\section{KEYWORDS}

Supracondylar Fracture of Femur, Intercondylar Extension, Limited Dissection, Anatomical Reduction.

HOW TO CITE THIS ARTICLE: Babu PA, Prasanth M. Comminuted fractures of distal femur- A study on limited dissection for internal fixation. J. Evolution Med. Dent. Sci. 2017;6(40):3181-3184, DOI: 10.14260/Jemds/2017/687

\section{BACKGROUND}

Supracondylar and intercondylar fractures of the distal femur are common fractures of femur. The high velocity trauma can result in this type of fractures with a variety of fracture patterns. These fractures often are unstable and comminuted and tend to occur in elderly or multiple-injured patients.(1) Because these fractures are in the vicinity of the knee joint and sometimes extend into the knee, retaining and regaining full knee motion and function may be difficult. There is high incidences of malunion, nonunion and infection.(2)

The classification of distal femoral fractures described by Müller et al and expanded in the AO/OTA classification is useful in determining treatment and prognosis (Fig. 1). It is based on the location and pattern of the fracture and considers all fractures within the transepicondylar width of the knee. Type A fractures involve the distal shaft only with varying degrees of comminution. Type B fractures are condylar fractures; type B1 is a sagittal split of the lateral condyle, type B2 is a sagittal split of the medial condyle and type B3 is a coronal plane fracture. Type $\mathrm{C}$ fractures are $\mathrm{T}$-condylar and $\mathrm{Y}$ condylar fractures; type $\mathrm{C} 1$ fractures have no comminution, type $\mathrm{C} 2$ fractures have a comminuted shaft fracture with two principal articular fragments and type C3 fractures have intraarticular comminution.

Financial or Other, Competing Interest: None.

Submission 11-04-2017, Peer Review 05-05-2017,

Acceptance 11-05-2017, Published 18-05-2017.

Corresponding Author:

Dr. P. Anil Babu,

\#5-54-120, 101 Suryodaya Residency,

6/18, Brodipet, Guntur-522002, Andhra Pradesh.

E-mail: anilpbabu@gmail.com

DOI: $10.14260 /$ jemds $/ 2017 / 687$

\section{(c) $($ ) $\odot$}

Various treatment methods were tried. In the 1960s, nonoperative treatment methods such as traction and cast bracing produced better results than operative treatment, because of the lack of adequate internal fixation devices. In 1966 Stewart, Sisk and Wallace from the Campbell Clinic retrospectively reviewed 213 supracondylar and intercondylar femoral fractures. Results were satisfactory in $67 \%$ of fractures treated non-operatively and in 54\% of fractures treated operatively. Delayed union or nonunion occurred in $9.7 \%$ of fractures treated with closed methods and in $29 \%$ of fractures treated operatively. Two-pin traction was recommended as the treatment of choice. In 1967 Neer, Grantham and Shelton also compared operative with non-operative treatment in 77 supracondylar and intercondylar femoral fractures with a minimum of 1 year of follow-up. In patients treated with nonoperative methods, $84 \%$ with displaced fractures had satisfactory results. The incidence of malunion and infection was $5.1 \%$, and the incidence of nonunion and severe knee stiffness (Range of motion of $<60$ degrees) was $2.6 \%$. The results for operatively treated fractures were far worse. Satisfactory results were obtained in only $5 \%$, malunions occurred in 31\%, infections and severe knee stiffness developed in $23 \%$ and the incidence of nonunion was $14 \%$. Most fractures treated operatively required postoperative immobilisation, because sufficient stability had not been obtained by the internal fixation devices. Non-operative treatment was recommended.

Complex AO type $\mathrm{C}$ fractures of the distal femur pose difficulty in reduction to get anatomical alignment because of comminution, multiple fragments in different orientations, soft tissue attachments which aid in the deformity and difficulty in getting anatomical reduction which make these as challenging injuries, often met with complications such as 
malunion and stiffness. Our study is done with limited dissection to avoid many complications explained above and to achieve anatomical reduction with a distal femur plate. During our study where an open reduction is planned as standard treatment for creating congruous joint, we have observed in this study by following a surgical tip to align the fragments in all aspects with limited dissection.

Open reduction and internal fixation of comminuted intercondylar and supracondylar fractures of the femur require extensive exposure and dissection. The surgical technique should get anatomical reduction with limited dissection. Open reduction and internal fixation of these difficult fractures are justified only if- (1) The joint surfaces can be restored anatomically, (2) Fixation is sufficiently rigid that external immobilisation is not required, (3) Rigidity of fixation is sufficient to allow early and active motion of the knee joint, and (4) The skin and soft tissues are satisfactory for a major operation.

Insertion of a 95-degree condylar blade plate is technically difficult. The broad surface area of the plate provides excellent fixation and resistance to bending and torsional forces. If the blade is inserted correctly into the condyles, anatomical alignment of the femur can be obtained by fixing the plate to the shaft of the femur. If the blade is inserted incorrectly, malalignment occurs. The blade plate is indicated for both supracondylar and intercondylar fractures of the femur. Fractures with extensive articular comminution may be better treated with a condylar buttress plate.(3)

To provide better exposure of the distal articular surface of the femur, Starr, Jones and Reinert used a modified anterior approach they called the "swashbuckler" approach. Cited advantages to this approach in addition to improved exposure are sparing of the quadriceps muscle bellies and a surgical scar that does not interfere with subsequent total knee arthroplasty. This approach is useful for fixation of distal femoral fractures with intra-articular involvement. Our study has followed limited dissection for the far cortex and posteriorly displaced fragments without causing further insult to the soft tissues and bone stripping. After an extensive dissection, patients may require reoperation for various reasons like persisting bone defect, delayed union and that require a planned staged bone grafting because of the metaphyseal defect after debridement of an open fracture.(4) Independent risk factors for reoperation to promote union and deep infection included diabetes and open fracture. Risk factors for proximal implant failure included open fracture, smoking, increased body mass index and shorter plate length.

\section{MATERIALS AND METHODS}

Our study is done with supracondylar fractures of femur with the following inclusion criterion: Type $\mathrm{C}$ of Muller. AO/OTA fractures of distal femur, soft tissue injury ranging from abrasions, contusion, (Fig. 2 and 3) lacerations, comminution on single or both supracondylar ridges. Our exclusion criterion was- Compound fractures with periosteal breach, any other associated injuries in the same limb, pre-existing malunions. We have included the cases presented to GGH, Guntur treated by Department of Orthopaedics from Jan 2007 to Dec 2016 for this observational study.

The patients were evaluated for comorbid conditions during initial assessment and pre-anaesthetic checkup. The patients who were having muscle deep lacerations are immobilised on a Braun splint for the soft tissues show healthy wound with approximating sutures after a thorough lavage.

On an average, the patients are operated on third day for technically compound fractures following the trauma and on fifth day with sutured lacerations for the compound wounds. For all the cases $10 \%$ Povidone iodine is painted on the intact skin during the two dressings before surgery. The fracture pattern included in the study are given in Table 1 .

Surgical technique: The patient is placed supine on a radiolucent table.

A small bolster is placed under the knee before draping. Another small bolster is draped in sterile towels and kept ready. Skin is thoroughly scrubbed and draping is done.

An incision is made on the lateral aspect to the supracondylar ridge to middle one-third of the femur; further it is distally extended across the patella. This incision gives access to the fracture except the medial condyle and posterior aspects of the condyles. As the regular incision like this is not giving access and the vastus needs to be retracted medially, much tension is already created, even distracters are used for the visibility of the displacement and comminution on that aspect was poor. In order to make use of the same incision in our study, the knee joint is further taken into flexion with a draped bolster which relaxes the taught gastrocnemius with its attachments on the posterior aspects of the femoral condyles. The relaxed gastrocnemius allows manoeuvring even with fingers or any blunt instruments to reduce the fractures on posterior aspects and medial condyles.

At this stage with reduced fracture on all aspects, the necessity of a graft can be assessed and kept. A distal femoral plate is kept on the lateral aspect and K-wires are used to hold all the fragments reduced. After this provisional fixation, the distal femoral locking plate is fixed with four or five cancellous and cortical screws in the shaft. The results of fracture fixation with limited dissection are monitored by the Range of Movements (ROM) regained by the patients in the postoperative period and during followup visits. The results are analysed by Chi squared statistic and $P$ value.

\section{RESULTS}

The results are assessed by the stability at the fracture site and smooth movements at the knee. All the fractures in our study are stable and the knee joint is moved through 90 degrees of flexion on the table. The patients are monitored with active ankle and toe movements and advised assisted ROM at knee, as tolerated from day five onwards as given in Table 2 for regained Range of Movements (ROM).

In terms of anatomical reduction, all the cases have both the condyles at the distal end aligned and confirmed by on table radiographs and post-operatively also.

The study with 29 cases, average ROM retained at day five is 30 degrees. All the patients are reviewed on day 11 for suture removal and improvements of ROM, which showed consistent improvement by second post-operative week to 60 degrees of flexion. Patients are discharged and first followup is at fourth post-operative week with 80 degrees of flexion possible for assisted movements. The improvement is much faster in patients with less soft tissue trauma around knee. The patients allowed partial weight bearing and active ROM from eighth week onwards; 8 cases of the study could retain 100 degrees of ROM.

The significance is tested in terms of improvement in the range of movements in the post-operative period. 
The Results were analysed as given in the following Tables

\begin{tabular}{|c|c|c|c|c|}
\hline $\begin{array}{c}\text { Fracture } \\
\text { Pattern }\end{array}$ & Cases & \multicolumn{2}{|c|}{ Reduction Required for } & Total \\
\hline & & $\begin{array}{c}\text { Medial } \\
\text { Displacement }\end{array}$ & $\begin{array}{c}\text { Posterior } \\
\text { Displacement }\end{array}$ & \\
\hline Type C 1 & 11 & 10 & 1 & 11 \\
\hline Type C 2 & 10 & 4 & 6 & 10 \\
\hline Type C 3 & 8 & 5 & 3 & 8 \\
\hline
\end{tabular}

Table 1. Case Distribution of Fracture Pattern

\section{Analysis}

The cases are monitored in the post-operative period with the improvement in the ROM regained by the patient and analysed as given in Table 2 .

\begin{tabular}{|c|c|c|c|c|c|c|c|}
\hline & $\begin{array}{l}\text { Оิ } \\
\text { เ̇ } \\
\text { เึ }\end{array}$ & $\sum_{N}^{n}$ & 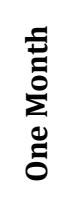 & 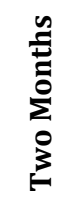 & 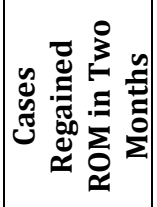 & 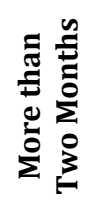 & 吾 \\
\hline \begin{tabular}{|l|} 
Type C 1 \\
\end{tabular} & $40^{0}$ & $60^{0}$ & $80^{0}$ & $100^{0}$ & 10 & 1 & 11 \\
\hline Type C 2 & $30^{0}$ & 50 & $80^{0}$ & $100^{0}$ & 8 & 2 & 10 \\
\hline Type C 3 & $20^{\circ}$ & $40^{\circ}$ & $60^{0}$ & $90^{\circ}$ & 7 & 1 & 8 \\
\hline
\end{tabular}

\begin{tabular}{|c|c|c|c|c|}
\hline \multicolumn{5}{|c|}{ Results } \\
\hline & C1 & C2 & C3 & Row Totals \\
\hline $\begin{array}{c}\text { Regained } \\
\text { ROM in 2 } \\
\text { Months }\end{array}$ & 10 & 8 & 7 & 25 \\
\hline $\begin{array}{c}\text { More than } \\
\text { Two } \\
\text { Months }\end{array}$ & 1 & 2 & 1 & 4 \\
\hline $\begin{array}{c}\text { Column } \\
\text { Totals }\end{array}$ & 11 & 10 & 8 & $\begin{array}{c}29 \text { Grand } \\
\text { Total }\end{array}$ \\
\hline $\begin{array}{c}\text { The Chi-square statistic is 0.5398. The p-value is .763458. } \\
\text { The result is not significant at p < 05. }\end{array}$ \\
\hline $\begin{array}{c}\text { Table 3. Analysis on Cases regained ROM in Two Months } \\
\text { and more than Two Months }\end{array}$ \\
\hline \multicolumn{5}{|c}{} \\
\hline
\end{tabular}

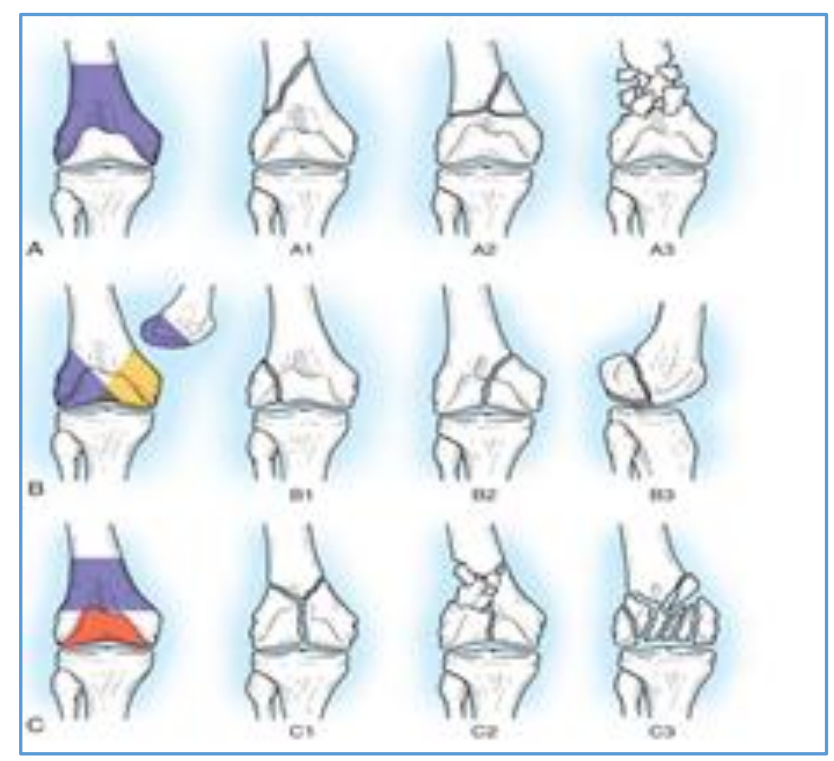

Figure 1. Classification of Distal Femoral Fractures described by Müller et al and Expanded in the AO/OTA Classification

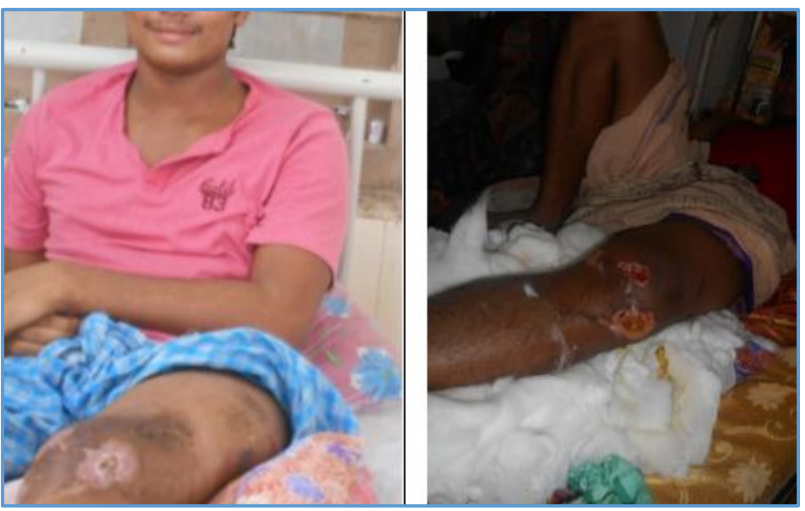

Figure 2. Soft Tissue Injuries

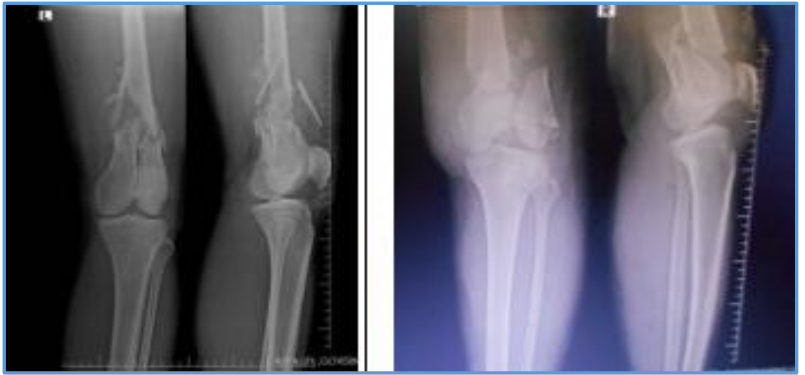

Figure 3. Radiographs Pre-Op

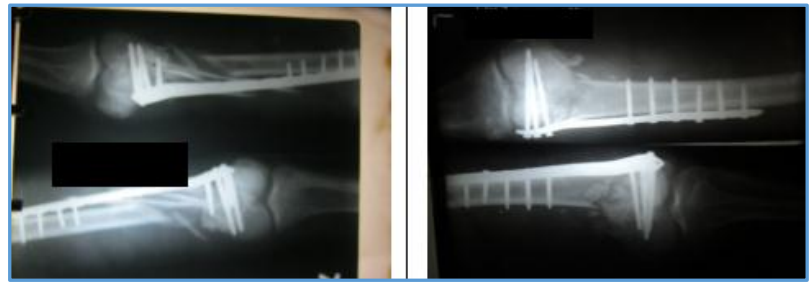

Figure 4. Radiographs Post-Op

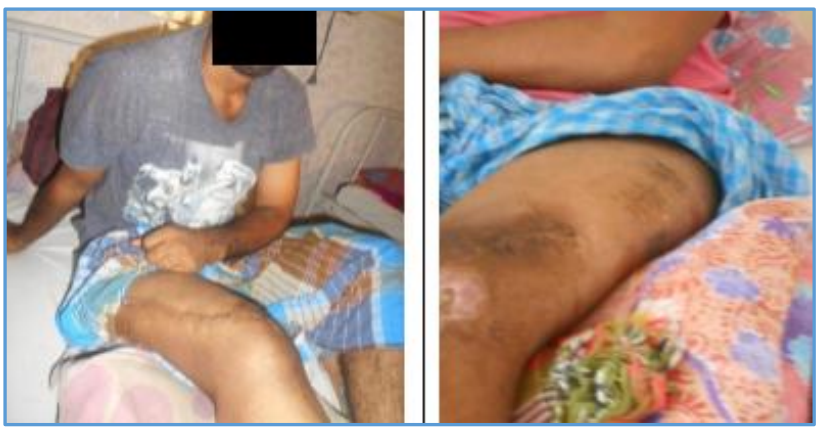

Figure 5. Scar

\section{DISCUSSION}

Distal femur fractures require anatomical reduction, at the same time the soft tissue dissection for open reduction should be limited to retain ROM to the maximum possible extent.

Distal femur fractures are often associated with prolonged healing and rehabilitation times, which increase substantially when complications occur.(5) Internal fixation of these fractures may be performed successfully with ABP or LCP. In our review of fractures that could be treated with either implants, patients treated with locking plates had more complications and non-unions requiring more secondary procedures to treat complications and to remove prominent implants. With our study, we would like to conclude that the comminution and the insult to the soft tissues can be better managed by limited dissection, wherein gastrocnemius can be 
kept relaxed to reduce and align the fragments on the medial and posterior aspects of the distal femur. This approach even provides access and reduction of Type $\mathrm{C}$ distal femur fractures under vision. As the dissection is limited, there is every chance for the patients to have less stiffness, less wound complications which finally aid in regaining and retaining ROM.

\section{CONCLUSION}

Comminuted fractures of distal femur can have multiplanar displacements, which are not very easy to reduce and fix. Dissection in all the planes is not possible and also not advisable, which can result in extensive scarring and can affect the final outcome in terms of range of movements. Simple reduction techniques can avoid extensive dissections. A minimal dissection with flexion at the knee can keep the gastrocnemius relaxed, which is essential to reduce all the components of the fracture. This minimal dissection avoids extensive scarring and thus produces better, retained range of movements.

\section{REFERENCES}

[1] Agrawal A, Kiyawat V. Complex AO type C3 distal femur fractures: results after fixation with a lateral locked plate using modified swashbuckler approach. Indian J Orthop 2017;51(1):18-27.

[2] Linn MS, McAndrew CM, Prusaczyk B, et al. Dynamic locked plating of distal femur fractures. J Orthop Trauma 2015;29(10):447-50.

[3] Canadian Orthopaedic Trauma Society. Are locking constructs in distal femoral fractures always best? A prospective multicenter randomized controlled trial comparing the less invasive stabilization system with the minimally invasive dynamic condylar screw system. J Orthop Trauma 2016;30(1):e1-6.

[4] Ricci WM, Streubel PN, Morshed S, et al. Risk factors for failure of locked plate fixation of distal femur fractures: an analysis of 335 cases. J Orthop Trauma 2014;28(2):83-9.

[5] Vallier HA, Immler W. Comparison of the 95-degree angled blade plate and the locking condylar plate for the treatment of distal femoral fractures. J Orthop Trauma 2012;26(6):327-32. 